\title{
Thermodynamic Design and Aerodynamic Analysis of Supercritical Carbon Dioxide Turbine
}

\author{
Dongbo Shi ${ }^{1, a}$, Liangliang $\mathrm{Li}^{1, \mathrm{~b}}$, Yanyao Zhang ${ }^{1, \mathrm{c}}$ and Yonghui Xie ${ }^{1, \mathrm{~d}}$ \\ ${ }^{1}$ School of Energy and Power Engineering, Xi'an Jiaotong University, Xi'an, China \\ asdb_xjtu@126.com, 'bliliangliang_xjtu@163.com, 'czhangyanyao@stu.xjtu.edu.cn, \\ dyhxie@mail.xjtu.edu.cn
}

Keywords: Supercritical carbon dioxide; Turbine; Thermodynamic design; Aerodynamic analysis Abstract. Supercritical carbon dioxide power cycle can reduce the power consumption and achieve higher system efficiency with the properties mutation phenomenon of supercritical fluids near the critical point. Turbine is the critical component of the heat-work conversion in cycle which has advantages of compact structure, small size and so on. It has significant engineering values for its design. In this study, based on one dimensional flow, the RNG k-epsilon turbulence model was used. The supercritical carbon dioxide turbine nozzle and impeller were designed preliminarily, and the three-dimensional flow model was established. The detailed parameters of the aerodynamic performance were obtained. The results are expected to provide the appropriate design scheme and reference data for the engineering application of the supercritical carbon dioxide turbine and power cycling system.

\section{Introduction}

Compared with the axial turbine, radial turbine has the advantages of compact structure, simple manufacturing process, low cost, and high efficiency at the design conditions of small flow, etc. Therefore, in recent years with the rapid development of engineering and technology, radial turbine is used more and more which had been overlooked over a period of time. The research of radial turbine at home and abroad is more concentrated in the conventional working fluid like gas or steam [1,2]. Supercritical carbon dioxide is a kind of supercritical fluid, its critical conditions are easy to achieve which the critical temperature is $31.1^{\circ} \mathrm{C}$ and the critical pressure is $7.4 \mathrm{MPa}$ [3]. Furthermore, it's an environmentally friendly natural working fluid. In this paper, the thermodynamic design and aerodynamic characteristics of supercritical carbon dioxide turbine are obtained based on one dimensional flow.

\section{Thermodynamic Design}

Based on one dimensional flow with the real gas state equation, flow continuous equation, momentum equation and energy equation, the characteristic thermodynamic parameters of turbine nozzle and impeller are obtained by advance calculation, scheme comparison and actual calculation which are shown in Table 1. And ultimately the geometric structure dimensions of turbine could be determined. The type line of the nozzle and the shape of the impeller in meridian plane are shown in Fig.1 and Fig.2.

Table 1 The Characteristic Thermodynamic Parameters

\begin{tabular}{cccc}
\hline Projects & Value & Projects & Value \\
\hline Amount of expansion gas [kg/s] & 8.646 & The efficiency of the flow channel & $89.75 \%$ \\
Inlet pressure [MPa] & 20 & Efficiency & $84.17 \%$ \\
Inlet temperature [K] & 373.15 & Shaft power [kW] & 198.06 \\
Outlet pressure [Mpa] & 7.8 & Rotating speed [rad/s] & 12504.49 \\
\hline
\end{tabular}




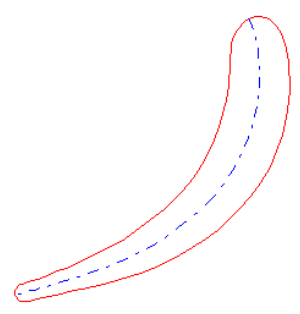

Fig.1 The type line of the nozzle

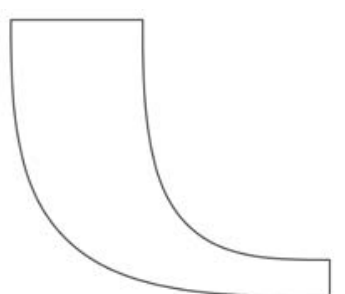

Fig. 2 The shape of the impeller in meridian plane

\section{Physical Model}

The structure of the computing area and the mesh of the single nozzle and impeller are shown in Fig.3. In the calculation, the hexahedral structured mesh is used, and a mesh size of 256156 is used in the single nozzle while 266178 used in the single impeller.
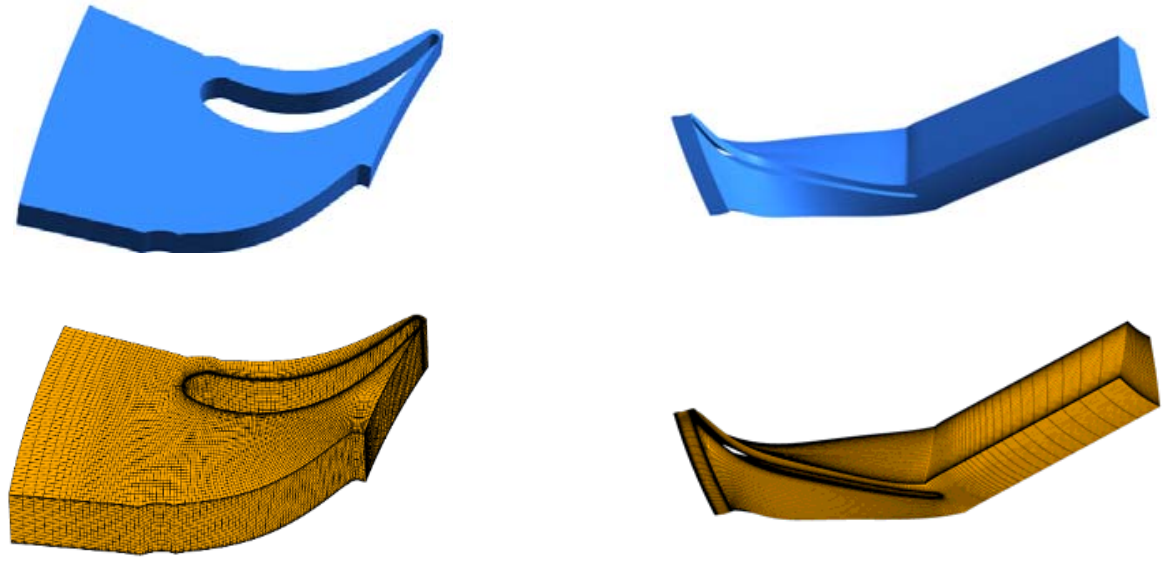

Fig.3 The structure of the computing area and the mesh of the single nozzle and impeller

\section{Results and Discussions}

Results for the Nozzle. The velocity distribution and an enlarged view of full circle nozzles are shown in Fig.4. The windward stagnation zone and the stagnation point at the leading edge of the nozzle blade can be observed clearly. The velocity gradient is large at about $60 \%$ relative chord place and the maximum velocity is increased to approximately $468 \mathrm{~m} / \mathrm{s}$. It should be noted that the fluid velocity at the nozzle outlet is slightly decreased, but the overall distribution is more uniform. And it maintains a higher velocity value.
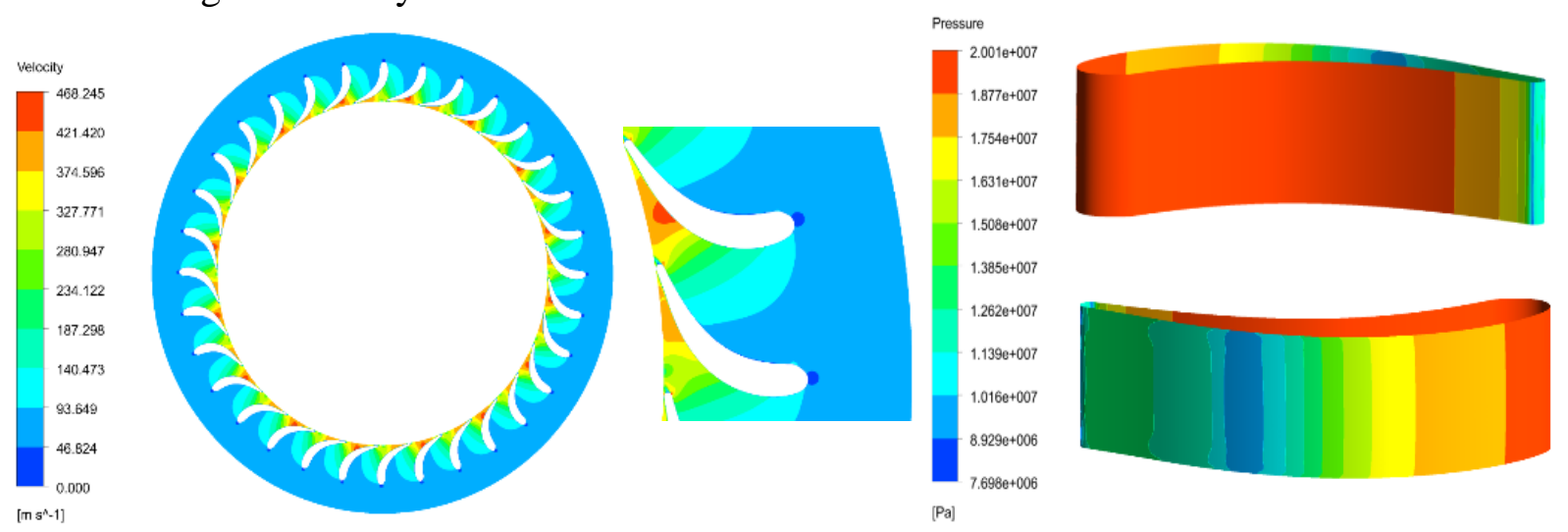

Fig.4 The velocity distribution of the nozzle

Fig.5 The pressure distribution of the nozzle blade

The pressure distribution of the single nozzle is shown in Fig.5. At the pressure side, the pressure is large and remained unchanged from the leading edge to about $85 \%$ relative chord place. From the 
followed position to the trailing edge, the pressure gradient is large and the lowest pressure is about $10 \mathrm{MPa}$ located at the nozzle outlet. The pressure distribution is completely different at the suction side. The greater pressure gradient is appeared near the leading edge and the pressure is reduced to about $9 \mathrm{MPa}$ at about $60 \%$ relative chord place. With the flow towards the downstream, the pressure of the suction surface rises slowly at first, and then it is decreased slightly at the outlet.

Results for the Impeller. Fig. 6 shows the absolute velocity distribution of the sections at the $10 \%$, $50 \%$ and $90 \%$ blade height respectively and partially enlarged views. It can be seen that the smaller velocity appears near the leading edge of the pressure side because of the vortex and the maximum velocity appears near the leading edge of the suction side. Close to the suction side, the flow is relatively steady and the velocity changes smoothly. With the increase of the blade height the flow is more relaxed.

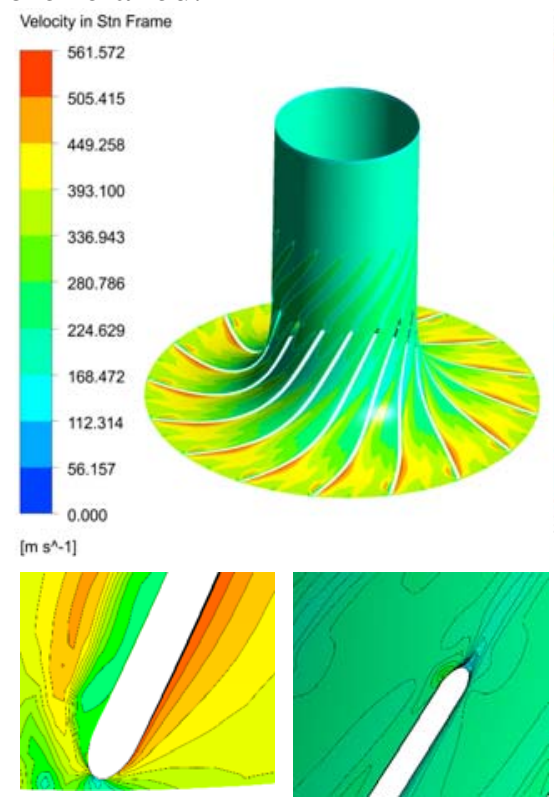

(a) 10\%blade height
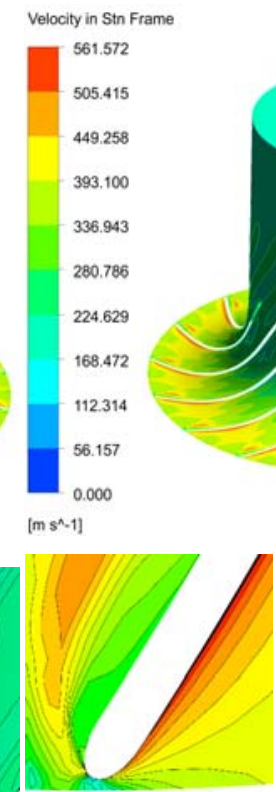

(b) $50 \%$ blade height
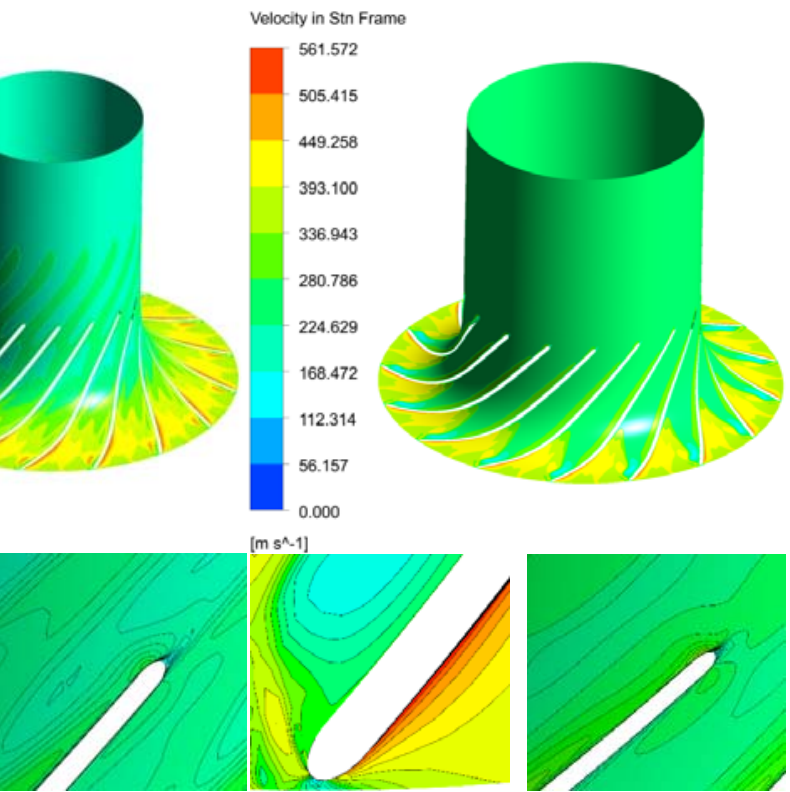

(c) $90 \%$ blade height

Fig.6 The absolute velocity distribution of the impeller

The pressure distribution of the impeller blade is shown in Fig.7. At the pressure side, the pressure gradually decreases along flowing direction. At the suction side, from the leading edge to about 35\% of the blade chord area, the pressure is gradually reduced. Pressure is increased and basically unchanged from the followed position to the trailing edge. At the same time, it should be noticed that there is a significant pressure gradient along the direction of the blade height in about $50 \%$ of the chord to the trailing edge region. This is due to the distortion of the blades and the growth of the blade height.

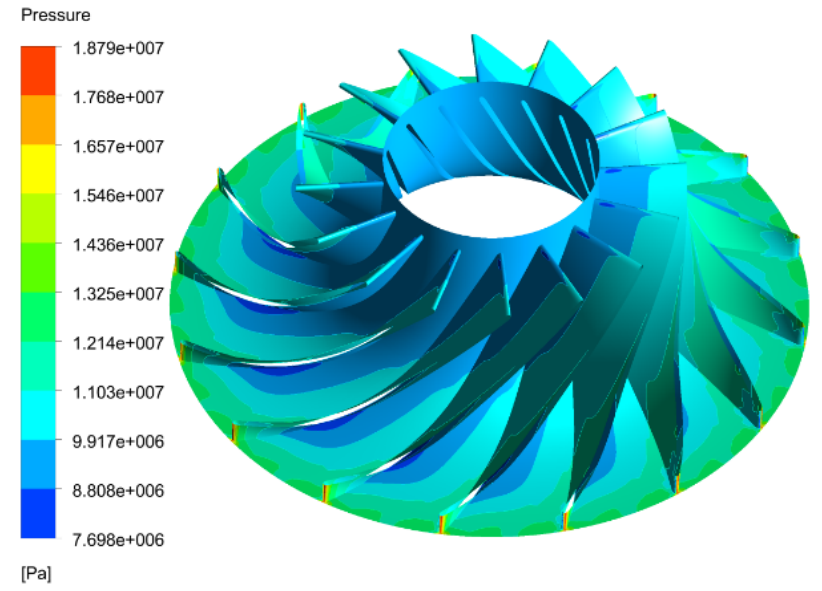

Fig.7 The pressure distribution of the impeller blade 
Results for Power and Efficiency. Table 2 shows the results comparison of numerical simulation and thermodynamic calculation. It shows that the power and efficiency of numerical simulation are lower, because of the supersonic flow in the turbine, the shock loss is produced.

Table 2 Results Comparison

\begin{tabular}{ccc}
\hline Projects & Thermodynamic calculation & Numerical simulation \\
\hline Amount of expansion gas [kg/s] & 2.276 & 2.8788 \\
Outlet temperature [K] & 744.12 & 747.697 \\
Outlet enthalpy [J/kg] & 948081.32 & 952350 \\
Shaft power [kW] & 198.056 & 187.00 \\
Efficiency & 0.8417 & 0.78499 \\
\hline
\end{tabular}

\section{Conclusion}

In this paper, the thermodynamic design and the detailed parameters of the aerodynamic performance of the supercritical carbon dioxide turbine are obtained. The main conclusions are as follows:

(1) Through the thermodynamic design of the turbine, the thermodynamic parameters of each feature point and the basic dimensions of main parts are obtained. The power of the designed turbine is $198.056 \mathrm{~kW}$ and the efficiency is $84.17 \%$.

(2) The velocity and pressure distribution are obtained while the RNG $k$ - $\varepsilon$ turbulence model is used in the numerical simulation.

(3) After numerical calculation, the power of the turbine is $187.00 \mathrm{~kW}$ and the efficiency is $78.50 \%$. Because of the supersonic flow in the turbine, the power and efficiency of numerical simulation are lower.

\section{References}

[1] Wasserbauer C A, Glassman A: T.FORTRAN Programming for Predieting Off-Design Performance of Radial In-fiow Turbines, NASA Teehnieal Report TN D-8063, 1975

[2] QiuXW, N Baines: Performance Prediction for High Pressure-Ratio Radial Inflow Turbines, proceedings of the ASME Turbo Expo.2007:945-956, 1868.

[3] V. Dostal, M.J. Driscoll, P. Hejzlar: A Supercritical Carbon Dioxide Cycle for Next Generation Nuclear Reactors, (2004). 